\title{
Raimond Castaing remembered
}

In 1951 Raimond Castaing submitted his thesis "Application of Electron Probes to Local Chemical and Crystallographic Analysis" to the University of Paris. This thesis, which was a magnificent piece of work, covered the experimental apparatus, quantitative procedures, applications, and Kossel patterns. Fortunately, after his move to the University of Toulouse, Raimond designed a Electron Microanalyser for ONERA that was to become the standard for commercial instruments.

It is without a doubt, that Raimond is the most dynamic person that I have had the pleasure to know. It was in 1956 , at the $1^{\text {st }} \mathrm{X}$-ray Optics meeting organized by Cosslett in Cambridge, where Raimond and I stayed at Sydney Sussex College where I had many fruitful discussions. These discussions also included the merits of French cuisine.

It was in August 1960 that Raimond, Tom Mulvey and Jim Long were guest lecturers at the first course on Electron Microanalysis at MIT. I will not forget the lecture that Tom was giving, Raimond became very upset and finally jumped to his feet and said "Tom that is not correct". Tom continued to finish the equation that he was writing and slowly turned around and said "I can understand your reaction if you had not thought the problem through completely". Raimond sat down very upset. I really don't remember which one was correct. Raimond came back as a guest lecture in July 1963. As usual his lecture mesmerized the participants.

It was in 1965 that Castaing, Deschamps and Philibert organized the IV Congress on X-ray Optics and Microanalysis. It was this meeting that set the standard of excellence, and up to now it has not been duplicated.

Raimond's vitality has not been limited to Electron Microanalysis, but his works in energy filtering in the electron microscope (Henry and El Hili), ion imaging and ion analysis (Slodzian, Hennequin), have opened up new developments in the analysis of materials.

My only regret is that it has been too long since Raimond and I have had a chance to have a Armagnac together.

Robert E. OGILVIE

M.I.T., Cambridge, Massachussetts, USA. 
The experimental model of the electron probe microanalyser, built by converting a CSF electrostatic electron microscope.

R. Castaing, Doctorate thesis, Paris 1951.

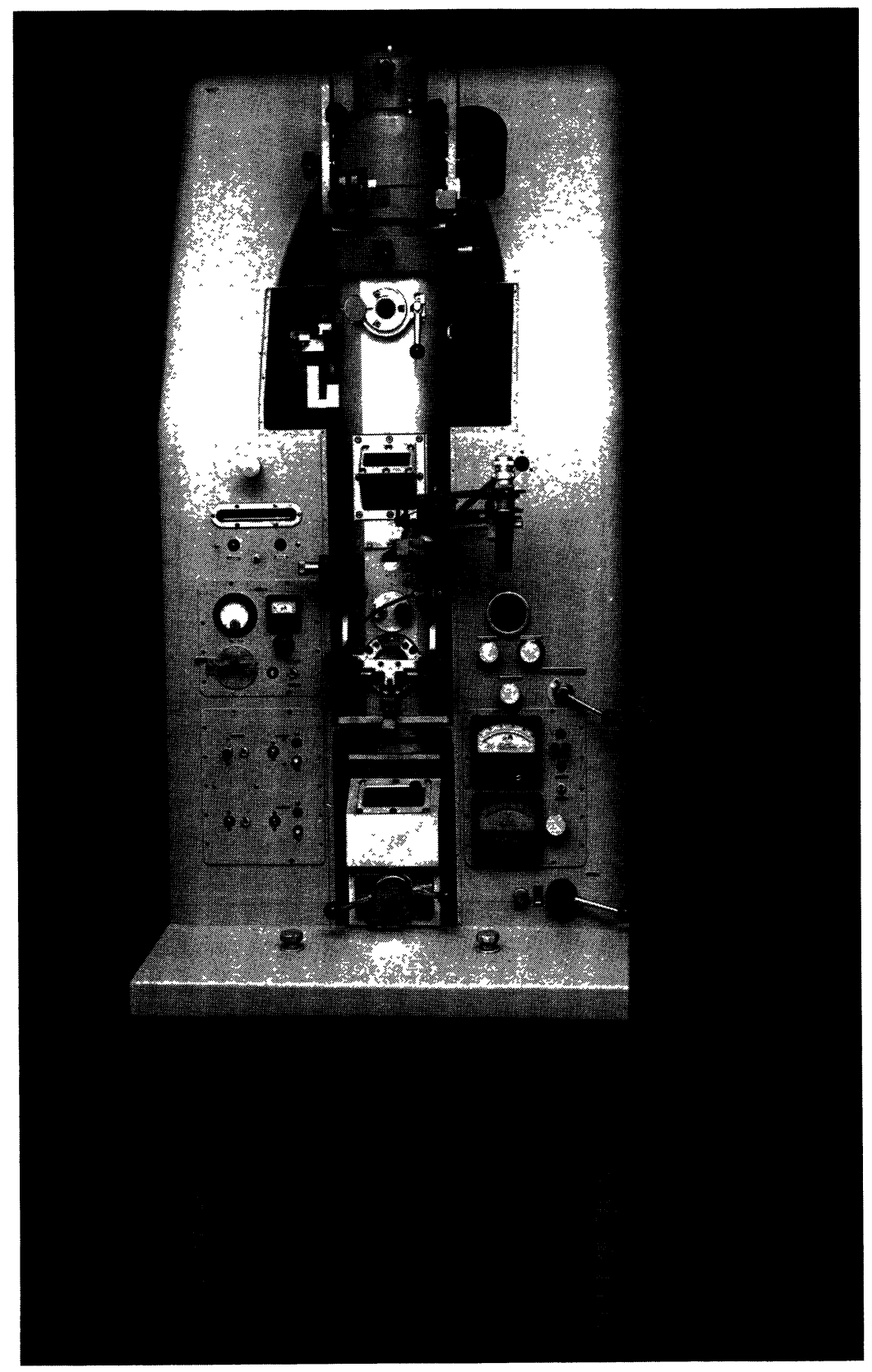

